\title{
Performance Evaluation of SSD Cache Based on DM-Cache
}

\author{
Jaemyoun Lee $^{\dagger}$. Kyungtae Kang ${ }^{\dagger \dagger}$
}

\begin{abstract}
The amount of data located in storage servers has dramatically increased with the growth in cloud and social networking services. Storage systems with very large capacities may suffer from poor reliability and long latency, problems which can be addressed by the use of a hybrid disk, in which mechanical and flash memory storage are combined. The Linux-based SSD(solid-state disk) uses a caching technique based on the DM-cache utility. We assess the limitations of DM-cache by evaluating its performance in diverse environments, and identify problems with the caching policy that it operates in response to various commands. This policy is effective in reducing latency when Linux is running in native mode; but when Linux is installed as a guest operating systems on a virtual machine, the overhead incurred by caching actually reduces performance.
\end{abstract}

Keywords : Cache, Input/Output, Storage, Disk, Evaluation

\section{DM-Cache를 이용해 구현한 SSD 캐시의 성능 평가}

\author{
이 재 면 ${ }^{\dagger}$.강 경 태 $^{\dagger \dagger}$
}

\begin{abstract}
요 약
최근 클라우드 서비스와 소셜 네트워크 서비스가 활성화되면서 스토리지 서버에 저장해야 할 데이터의 용량이 급격히 증가하고 있으며, 사 용자의 고품질 미디어 데이터에 대한 높은 수요는 이러한 경향을 더더욱 가속화하고 있다. 이와 더불어 데이터의 효율적 참조를 통한 처리시간 감소는 이미 과거로부터 꾸준히 요구되어온 시스템 설계 주 고려사항이다. 이런 이유로 하이브리드 디스크의 효율적인 사용에 대한 많은 기술 연구가 진행되고 있다. 그 핵심이라고 할 수 있는 리눅스 기반 SSD 캐시 기법은 내장된 DM-cache를 활용하여 구현하는데, 현재 이에 대한 최 적화 관련 정책 연구가 많이 부족한 실정이다. 본 연구에서는, 다양한 환경에서 성능 평가를 통하여 현재 제공되고 있는 DM-cache의 문제점을 파악하였다. 그 결과, 일반 운영체제에서 실험한 $\mathrm{DM}-\mathrm{cache}$ 는 읽기 명령 시 나름대로의 효과를 보고 있지만, 특히 가상 머신이 탑재된 운영체 제 환경에서는 DM-cache의 사용으로 인한 성능 개선을 찾을 수 없었으며 오히려 캐시 오버헤드로 성능 저하가 발생함을 확인하였다.
\end{abstract}

키워드 : 캐시, 입출력, 저장장치, 디스크, 평가실험

\section{1. 서 론}

클라우드 서비스가 보편화됨에 따라 빅데이터와 함께 스 토리지 산업이 급격하게 발전하였다. 그러나 하드디스크 기 술은 여러모로 한계에 부딪치고 있다. 용량 및 집적도 한계 를 극복하기 위한 다양한 방법이 시도되었지만, 현재 상용 화한 Shingled Magnetic Recording(SMR) 방식은 오히려

\footnotetext{
※ 이 논문은 2013년도 정부(미래창조과학부)의 재원으로 한국연구재단의 지 원을 받아 수행된 기초연구사업(No. NRF-2013R1A1A1059188)이고, 미래 창조과학부 및 정보통신산업진흥원의 $\mathrm{IT} / \mathrm{SW}$ 창의연구과정의 연구결과로 수행되었음(NIPA-2013-H0502-13-1061).

† 준 회 원 : 한양대학교 컴퓨터공학과 석 - 박사통합과정

†† 종신회원 : 한양대학교 컴퓨터공학과 조교수

Manuscript Received: July 23, 2014

First Revision: September 12, 2014

Accepted : September 12, 2014

* Corresponding Author: Kyungtae Kang(ktkang@hanyang.ac.kr)
}

요청 처리 속도의 저하를 야기한다[1]. 스핀들 디스크(spindle disk)는 물리적인 모터를 사용하는 디스크를 말하고, 이로 인한 태생적 한계를 벗어나기 쉽지 않다. 대안으로 플래시 메모리(flash memory) 기반의 Solid-State Disk (SSD)가 있 다. 속도, 밀집도, 저전력, 내구성 등 많은 장점을 가진 $\mathrm{SSD}$ 는 적절한 대안으로 주목받았으나, 운영체제와의 호환성, 높 은 가격, 낮은 용량이 단점으로 지적받고 있다[2].

이러한 이유로 하드디스크와 $\mathrm{SSD}$ 를 동시에 사용하는 하이 브리드 디스크 연구가 주목받고 있다. 하이브리드 디스크의 핵심 기술은 $\mathrm{SSD}$ 캐시이다. 즉, 캐시 정책에 따라 그 성능이 매우 달라진다. 하이브리드 디스크는 상용화된 제품으로도 개 발되지만, 소프트웨어 모듈을 이용한 가상 디스크로 구현되기 도 한다. 가상 디스크로 구현된 하이브리드 디스크의 성능을 최대화할 캐시 정책은 아직 연구가 부족한 상황이다. 
우리는 최적화 캐시 정책을 연구하기에 앞서, 캐시 작업 을 담당하는 DM-cache의 성능을 평가하고, 그 결과를 바탕 으로 현재 $\mathrm{DM}-$ cache 정책의 문제점을 진단한다. 또한, 가 상 머신에서 DM-cache의 성능을 평가하고, 문제점을 진단 한다.

클라우드 서비스가 발전하면서 가상 머신은 매우 중요한 기술로 자리매김하였다. 최근, 서버급 컴퓨팅 환경뿐만 아니 라 개인 사용자 컴퓨팅 환경에도 프로세서의 성능 향상 및 멀티 운영체제 환경 구축 등 다양한 이유로 가상화 기술을 사용하고 있다. 그러므로 가상 머신을 위한 DM-cache 성능 평가는 앞으로 $\mathrm{SSD}$ 캐시 기법 연구에 있어 중요한 평가 요 소이다.

본 논문은 총 5절로 구성되어있다. 제2절에서는 관련 연 구를 소개하고, 제3절에서는 DM-cache에 대해서 소개한다. 제4절에서는 실험 환경을 제시하고, 실험 결과와 함께 분석 한 내용을 기술한다. 제5절에서 결론을 맺고 향후 연구에 대해서 검토한다.

\section{2. 관련 연구}

오랫동안 디스크 기술이 발전하면서 하드디스크 기술은 이미 한계점에 도달했다. 집적도 한계를 극복하기 위해, Perpendicular Magnetic Recording(PMR) 방식을 SMR, 또는 Heat-Assisted Magnetic Recording(HAMR), bit-patterned media 방식으로 대체하는 연구가 진행 중이다[3-5]. 하지만, 이런 기술은 집적도 향상에 초점을 맞추고 있어, 디스크 고 속화 한계를 극복하진 못한다. 디스크 처리 속도를 향상시 키기 위해서는 무엇보다 스핀들 모터(spindle motor)의 한계 를 극복해야 한다. 스테핑 모터(Stepping motor)로 구성된 스핀들 모터는 한쪽 방향으로 정속 주행하며, 헤더가 데이 터를 읽을 수 있도록 도와준다. 한 방향으로 회전하기 때문 에 지나간 섹터는 다시 한 바퀴 돌 때까지 접근할 수 없다. 추가적으로, 모터 구동 시 발생하는 진동과 발열 때문에 구 동력을 $10,000 \mathrm{RPM}$ 이상으로 올리는 것을 피한다. 또한, 스핀 들 모터는 물리적인 모터이기 때문에 소비 전력이 매우 크 다. 대기 상태의 평균 소비 전력은 $3.4 \mathrm{~W}$ 로 컴퓨터 구성 요소 중 가장 많은 전력을 소비하는 장치이다[6]. 전력 공급이 제 한된 모바일 기기는 소비 전력에 민감하기 때문에 스핀다운 (spin-down) 기술을 활용하여 소비 전력을 줄이고 있다[7].

위 문제를 해결하기 위해 플래시 메모리 기반의 디스크가 출시되고 있다. 플래시 메모리 디스크는 반도체로 구성되어, 스핀들 모터가 없다. 즉, 어느 셀에 접근하든 접근 속도의 차이가 거의 없고, 평균 접근 시간 역시 하드디스크에 비해 상당히 빠르다. 모터가 없기 때문에 소비 전력은 현저히 적 다[7]. 스핀다운한 하드디스크에 접근을 요청하면, 먼저 스핀 들 모터를 정속으로 구동한 후에 요청을 처리할 수 있기 때
문에 지연 시간이 발생한다(약 4.5초). 그에 비해 플래시 메 모리 기반의 디스크는 디지털 논리 회로를 이용하여 저전력 모드로 전환하기 때문에 그 지연 시간이 측정할 수 없을 정 도로 작고, 무시할 수 있다.

물론 플래시 메모리 기반의 디스크가 모든 면에서 하드디 스크보다 좋은 것은 아니다. 운영체제와의 호환성, 가격, 제 한된 수명 등 아직 많은 단점을 가지고 있다[2]. SSD 사용 자가 많아지면서 운영체제 제조사에서 호환성을 보장하고, 가격 역시 내려가고 있다. 그러나 하드디스크 기술 역시 발 전하기 때문에 그 격차를 역전하기는 쉽지 않다. 테이프 스 토리지가 현재도 사용되는 것과 비슷하다.

결국에 하드디스크와 플래시 메모리 디스크의 장점만을 공유하는 하이브리드 디스크가 연구되고 있다. 하이브리드 디스크는 하드디스크의 많은 용량을 가지면서, 자주 접근하 는 파일은 플래시 메모리로 이주시켜 빠른 접근시간을 보장 하는 기술이다. 이 연구의 핵심은 어느 데이터를 플래시 메 모리에 저장할지[8], 플래시 메모리 용량이 부족할 경우 어 떤 데이터를 희생해야 하는지를[9] 결정하는 캐시 정책이다. 관련 연구들이 많이 있으며, 상용화된 제품으로도 판매하고 있다[10].

그러나 이런 하이브리드 디스크 제품은 고가이면서 유용 성이 떨어진다. 일반 사용자가 구매하기에는 $\mathrm{SSD}$ 와 가격 차이가 크지 않아, 가격 대비 효율이 없다. 대규모 스토리지 서버를 보유한 데이터센터에서도 Total Cost of Ownership (TCO) 관점에서 고가의 하이브리드 디스크는 부정적이기에 하이브리드 디스크의 제품 도입 사례가 드물다.

앞서 말했듯이 하이브리드 디스크의 핵심은 캐시 정책이 다. 어떤 데이터를 캐시할 것이고, 얼마나 캐시할 것인지를 결정하는 정책이 하이브리드 디스크의 성능을 판가름한다. 이런 정책은 입출력 요청 패턴에 따라서 매우 다른 성능을 보인다. 모든 요청 패턴에 최적화된 정책은 사실상 불가능 하기 때문에 각 사용 환경에 적합한 정책이 필요하다. 그러 나 하이브리드 디스크 제품은 이 정책을 변경하기 쉽지 않 다. 상황이 이러다 보니 데이터센터 스토리지 서버 운영자 는 하이브리드 디스크 제품을 이용하지 않고, 직접 구현한 다. 대표적인 구현 방법은 기존 하드디스크와 플래시 메모 리 기반의 디스크를 가상 디스크로 구현하고 시스템 레벨에 서 캐시 작업을 수행하는 기술이다[11-14]. 대표적으로 장치 맵퍼(device mapper)가 있으며, 리눅스 커널 3.9부터 정식 커널에 포함되어 배포되고 있다[13]. 이는 기본적으로 플래 시 메모리 기반의 디스크를 캐시로 사용하는 기법이다. 다 만, 아직 초기 기술로 정책이 최적화되지 않아, 적응 가능성 이 낮다. 정식 커널에 포함된 만큼 앞으로의 발전 가능성 및 다른 패키지와의 호환성이 높기 때문에 연구가 매우 필 요하다. 본 연구는 관련 연구에 앞서 현재 DM-Cache의 성 능을 평가하고, 문제점을 진단하고자 한다. 


\section{DM-Cache}

DM-cache는 하드디스크로부터 플래시 메모리 기반의 $\mathrm{SSD}$ 로 캐시하는 장치 맵퍼 기법으로, 데이터 블록 단위 에 최적화되어있다. 리눅스 공식 커널 3.9 상위 버전에서 공식 지원하고 있다. 그 목적은 자주 접근하는 파일의 요 청 처리량과 반응시간(latency)의 성능 향상이다. DMcache는 3가지의 장치를 요구한다. 첫째, 일반 하드디스크 에 해당하며 원본 데이터를 저장하는 기본 장치(origin device)이다. 두 번째, 주로 플래시 메모리 기반의 SSD에 해당하며, 캐시 공간으로 사용하는 캐시 장치(cache device)이다. SSD가 아니더라도 기본 장치보다 성능이 좋 은 비휘발성 디스크라면 캐시 효과를 볼 수 있다. 마지막 으로, DM-cache가 동작하면서 필요한 정보를 저장하는 메타데이터 장치(metadata device)이다. $\mathrm{SSD}$ 나 RAM에 할당한다. DM-cache는 사용자 설정에 따라 캐시 블록 크 기, 캐시 정책, 마이그레이션 조정값(throttling), 디스크에 저장되는 메타데이터 등을 조절할 수 있으며, 이에 따라 $\mathrm{DM}-\mathrm{Cache}$ 의 성능이 달라진다.

DM-cache는 메타데이터 라이브러리로 씬 프로비저닝 (thin-provisioning) 라이브러리를 재사용한다. 메타데이터 장치에 저장하는 정보는 어떤 블록을 캐시하였는지, dirty 한 블록은 어떤 것인지 등을 가지고 있다. 커널에 포함된 $\mathrm{DM}-\mathrm{Cache}$ 는 write-back 정책과 write-through 정책을 포함하고, write-back 정책을 기본으로 한다. Writeback 정책은 쓰기 요청 시 cache hit가 발생하면 캐시 장 치에 있는 데이터만 갱신하고, 해당 블록을 dirty 블록으 로 변경한다. 추후 dirty 블록이 희생되면, 그때 기본 장치 에 있는 데이터를 최신 데이터로 갱신한다. 반면 writethrough 정책은 쓰기 요청 시 cache hit 여부에 관계없이 항상 캐시 장치는 물론 기본 장치에도 쓰기 요청을 수행 한다. 즉, cache hit가 있으면 캐시 장치와 기본 장치의 데 이터를 모두 갱신하고, 그렇지 않으면 기본 장치 데이터 만 갱신한다.

하드웨어 최소 요구 사항은 느린 디스크(기본 장치) 하나 와 빠른 디스크(캐시 장치, 메타데이터 장치) 하나씩이다. $\mathrm{RAM}$ 을 사용하지 않는 경우 $\mathrm{SSD}$ 의 파티션을 나누어 캐시 장치와 메타데이터 장치를 구분해주어야 한다. 소프트웨어 요 구 사항은 dmsetup 유틸리티를 필수로 요구하고, Logical Volume Management(LVM)가 있으면 보다 쉽게 가상 디스 크를 만들어 사용할 수 있다. 본 연구에서도 LVM을 사용하 여 실험하였다.

\section{4. 성능 평가}

\section{1. 실험 환경}

우리는 플래시 메모리 캐시 정책을 연구하기에 앞서 리눅 스 공식 커널에서 제공하는 순수 DM-cache 성능을 평가했
다. 실험한 컴퓨터의 사양은 Table 1 과 같으며, 애플리케이션 실행 시간과 IOzone 벤치마킹을 이용하여 성능을 평가했다.

Table 1. Experimental conditions

\begin{tabular}{c|c}
\hline CPU & Intel Core i3-2100 3.1GHz \\
\hline RAM & $4 \mathrm{G}$ \\
\hline Host OS & Linux(Fedora 20) \\
\hline Kernel & 3.14 .2 \\
\hline File Systems & Ext4 \\
\hline HDD & Seagate ST1000DM003 \\
\hline SSD & Samsung MZ-7PC256 \\
\hline
\end{tabular}

또한, 호스트 컴퓨터에 DM-cache를 설정하고, 가상 머신 guest OS의 디스크 성능을 평가했다. 전가상 머신 VMware 를 이용하여 일반 하드디스크와 DM-cache 디스크에 게스 트 이미지를 만들고, IOzone 성능 평가를 하였다.

$\mathrm{DM}$-cache는 dmsetup 명령으로 설정하는데, 기본 장치를 위해 하드디스크에 $100 \mathrm{~GB}$ 파티션을 만들었다. 그리고 캐시 장치와 메타데이터 장치를 위해 $\mathrm{SSD}$ 에 $10 \mathrm{~GB}$ 파티션을 만 들고, $\mathrm{LVM}$ 을 이용하여 $512 \mathrm{MB}(5 \%)$ 를 메타데이터 장치로 할당했다. 나머지는 캐시 장치로 할당했다. 캐시 블록 크기 는 $256 \mathrm{~KB}$ 로 하였으며, 정책은 write-back 정책을 사용하였 다. 본 실험에서 사용하는 모든 디스크는 ext4 파일시스템으 로 포맷하였다.

\section{2. 실험 결과}

1) 애플리케이션 실행 시간

디스크의 캐시 효과를 확인하기 위해 애플리케이션 실행 시간을 측정하였다. 애플리케이션 실행 시간은 사용자가 컴 퓨터를 사용하면서 가장 민감하게 느끼는 시간이므로, 이 실험은 매우 의미 있다.

대부분의 애플리케이션은 실행하면서 매번 동일한 파일을 요청한다. 이렇게 자주 요청받는 파일을 캐시하고 있으면, 다음번 실행할 때 빠른 응답 시간을 보장한다.

우리는 보다 명확한 캐시 효과를 확인하기 위해 애플리케 이션 실행 시, 많은 양의 파일을 요청하는 이클립스(Eclipse) 와 오픈오피스(OpenOffice Writer)의 실행 시간을 측정했다. 또한, 두 애플리케이션과 다르게 요청 양이 적은 파이어폭 스(Firefox)의 실행 시간도 측정했다.

그 결과는 Fig. 1과 같다. DM-cache를 이용하면서 처음 에는 일반 하드디스크에서 실행한 것보다 느린 결과를 보인 다. 그러나 계속 실행할수록 그 차이가 줄어들면서, 세 번째 이상 실행할 때는 오히려 DM-cache를 이용한 디스크가 더 빠른 성능을 보인다. 처음에는 캐시 작업으로 인한 오버헤 드 때문에 더 느린 성능을 보이지만, 캐시가 일어나면서 응 
답 시간이 줄어드는 것을 볼 수 있다. 이클립스와 오픈오피 스, 파이어폭스 애플리케이션은 각각 $87 \%, 77 \%, 95 \%$ 실행 시간이 줄어들었다.

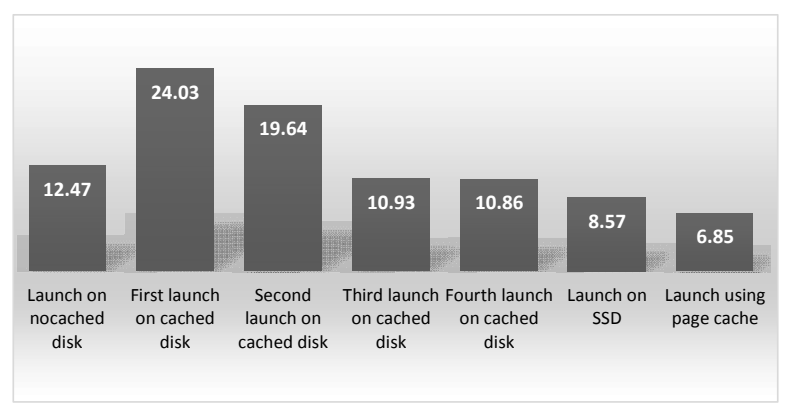

(a) Eclipse application

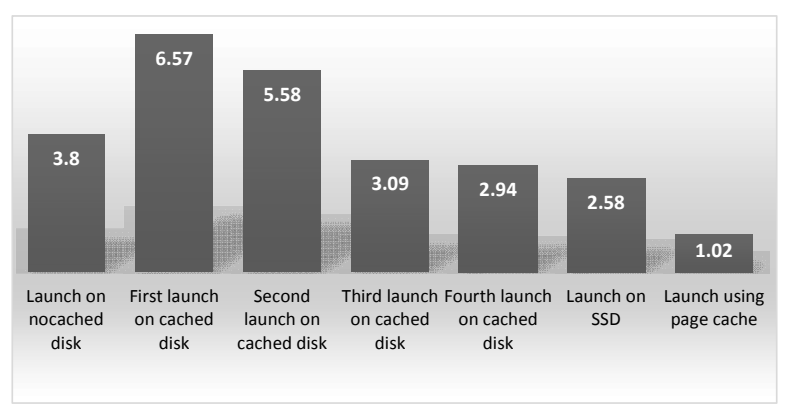

(b) OpenOffice Writer application

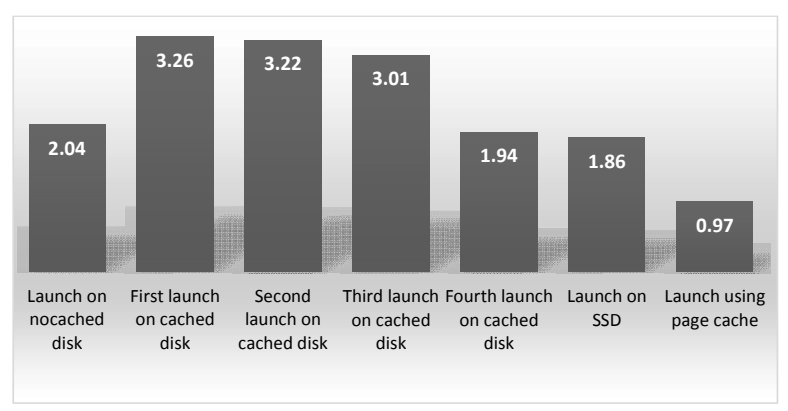

(c) Firefox application

Fig. 1. Comparison of applications launching time

이 실험은 페이지 캐시를 사용하지 않고 진행했다. 페이 지 캐시는 이클립스를 실행하면서 요청받은 데이터를 모두 $\mathrm{RAM}$ 에 저장하고 다음에 cache hit가 발생하면, RAM에서 데이터를 읽기 때문에 가장 빠른 응답 시간을 보여준다. 사 실 $\mathrm{SSD}$ 가 하드디스크에 비해 빠르지만, RAM보다는 느리 기 때문에 $\mathrm{SSD}$ 캐시가 페이지 캐시보다 성능이 더 좋을 수 는 없다. 단, 페이지 캐시는 크기가 크지 않아, 매번 효과를 볼 수 없다. 또한, RAM은 비휘발성 메모리이기 때문에 컴 퓨터를 재부팅하면 모든 캐시 데이터가 사라진다. 반면, $\mathrm{DM}-$-cache는 매우 큰 용량의 캐시를 가질 수 있으며, 비휘
발성 스토리지에 캐시 데이터를 저장하므로 재부팅 후에도 캐시 정보가 남아있다.

$\mathrm{SSD}$ 캐시를 해도 모든 데이터가 캐시 되는 것은 아니기 때문에 SSD에서만 실행한 결과보다는 느리다. DM-cache는 무작위 접근 데이터에 초점을 맞추어 캐시하기 때문에 순차 접근이 많으면 캐시 적중률(cache hit ratio)이 줄어든다. 이 경우 $\mathrm{SSD}$ 보다는 느린 결과를 보인다.

실험 결과에 따르면 페이지 캐시보다는 느리지만, 하드디 스크보다는 빠르다. 그러므로 두 디스크 계층 사이에 캐시 디스크가 있다면 성능을 높일 수 있고, $\mathrm{DM}-$ cache가 그 역 할을 충실히 하고 있음을 증명하였다.

\section{2) IOzone 성능 평가}

IOzone은 일반적인 파일 입출력을 디스크에 요청하고, 디 스크 성능을 평가하는 벤치마킹 툴이다. 다음과 같은 다양 한 명령이 있고, 모든 명령에 대한 성능을 평가하였다.

- Normal write: 디스크에 새로운 데이터를 기록하는 명령 이다. 이 명령의 응답 시간은 새로운 데이터를 기록하는 오버헤드뿐만 아니라 그 데이터를 어디에 기록해야 하는 지 판단하는 오버헤드도 포함한다. 후자와 같은 데이터를 메타데이터라고 한다.

- $\mathrm{Re}^{-}$write: 디스크에 이미 쓰인 데이터를 새로 갱신하는 명령이다. 데이터를 갱신하는 오버헤드가 있을 뿐, 메타데 이터는 이미 존재하여 재기록할 필요가 없기 때문에 normal write보다 오버헤드가 적다.

- Normal read: 존재하는 파일을 처음부터 차례로 읽는 명 령이다.

- Re-read: 한 번 읽은 데이터를 다시 읽는 명령으로 캐시 에 의해 성능 향상이 읽어나는 것을 측정할 수 있다.

- Random read: 존재하는 파일의 블록을 무작위로 읽는 명 령이다. 캐시 크기, 또는 디스크의 수, 블록 탐지 속도 등 에 의해 성능이 달라진다. 특히, 하드디스크는 스핀들 모 터 때문에 매우 느린 속도를 보이는 반면, SSD는 순차 방식과 큰 차이를 보이지 않는다. 경우에 따라 더 빠른 속도를 보일 수 있다.

- Random write: 파일에서 무작위로 데이터 블록을 선택하 여 데이터를 갱신하는 명령이다. 캐시 크기, 또는 디스크 의 수, 블록 탐지 속도 등에 의해 성능이 달라진다. 특히, 하드디스크는 스핀들 모터 때문에 매우 느린 속도를 보 이는 반면, $\mathrm{SSD}$ 는 순차 방식과 큰 차이를 보이지 않는다. 경우에 따라 더 빠른 속도를 보일 수 있다.

- Backward read: 파일을 뒤에서부터 읽는 명령이다. 특정 애플리케이션은 기록한 내용을 뒤에서부터 읽는 경우가 
있어서, 이를 위한 성능 평가이다. 대부분의 운영체제가 앞에서부터 차례로 읽는 기법에 초점을 맞추지만, 소수의 운영체제는 뒤에서부터 거꾸로 읽는 기법에도 초점을 맞 추고 있다.

- Record re-write: 파일 내 특정 영역의 데이터를 계속 갱 신하는 명령이다. 갱신하는 데이터의 크기와 Central Process Unit(CPU) 데이터 캐시, 운영체제 캐시 크기에 따라서 성능이 크게 달라진다.

- Stride read: 일정 크기를 건너뛰면서 읽는 명령이다. 대 부분의 운영체제에서 이 명령을 위한 기법을 제공하지 않지만, 경우에 따라 병목현상이 발생할 수 있는 명령으 로 성능 평가가 필요하다.

- Fwrite: 라이브러리 fwrite()를 이용해 새로운 데이터를 기록하는 명령이다. 라이브러리 fwrite()는 사용자 공간에 있는 버퍼를 이용하기 때문에 이와 관련된 성능을 측정 할 수 있다. 버퍼의 크기와 요청 데이터의 크기에 따라서 운영체제 시스템 콜의 수를 줄일 수 있다. 이 명령은 새 로운 데이터를 기록하는 오버헤드와 메타데이터를 만들 고 쓰는 오버헤드를 포함한다.

- Re-fwrite: 라이브러리 fwirte()를 이용해 이미 쓰인 데이 터를 갱신하는 명령이다. 라이브러리 fwrite()는 사용자 공간에 있는 버퍼를 이용하기 때문에 이와 관련된 성능 을 측정할 수 있다. 버퍼의 크기와 요청 데이터의 크기에 따라서 운영체제 시스템 콜의 수를 줄일 수 있다. 기존 데이터를 갱신하기 때문에 메타데이터를 만들고 쓰는 오 버헤드가 없다.

- Fread: 라이브러리 fread()를 이용해 존재하는 파일에서 데이터를 읽는 명령이다. 라이브러리 fread()는 사용자 공 간에 있는 버퍼를 이용하기 때문에 이와 관련된 성능을 측정할 수 있다. 버퍼의 크기와 요청 데이터의 크기에 따 라서 운영체제 시스템 콜의 수를 줄일 수 있다.

- Re-fread: 라이브러리 fread()를 이용해 한 번 읽은 데이 터를 다시 읽는 명령이다. 운영체제에서 제공하는 캐시의 성능에 의해 결과가 달라진다. 또한, DM-cache에 의해서 도 결과가 달라진다.

Fig. 2에 IOzone을 평가한 결과를 표시하였다. 표시한 값 은 DM-cache 디스크의 성능을 측정한 값에서 일반 하드디 스크의 성능을 측정한 값을 뺀, 차이를 나타냈다. 즉, 양수는 캐시 했을 때 성능이 더 높은 것을 의미하고, 음수는 캐시 전이 더 성능이 좋았음을 의미한다.

Normal write는 테스트 데이터의 크기가 작으면, DM-cache 디스크가 더 빠른 성능을 보인다. 그러나 테스트 데이터의 크기가 커지면 종종 성능이 비슷하다. 이는 벤치마 킹 툴의 동작 방식상 쓰기 명령을 반복하기 때문에 종종 블
록을 캐시하고 write-back이 일어났음을 의미한다. Re-write 는 작은 테스트 데이터에서 좋은 성능을 보이나, 특정 크기 부터 성능이 급격히 저하된 모습을 보인다. 테스트 데이터 가 작을 때는 블록의 개수가 적어 캐시가 일어난다. 그러나 DM-cache는 순차 요청에 대해서는 캐시하지 않기 때문에 블록 개수가 많아지면서 순차 요청이 일어났다. 즉, 테스트 데이터가 커지면서 캐시가 일어나지 않았다.

Normal read는 테스트 데이터의 크기에 상관없이 대체로 DM-cache 디스크가 더 빠른 모습을 보인다. 다만, 테스트 데 이터의 크기가 커질수록 그 차이가 줄어든다. Re-read에서 DM-cache의 효과를 확인할 수 있다. 최고 응답 속도도 빠르 며, normal read에서 가끔 발생한 음수 구간이 없다. Random read도 DM-cache 디스크가 더 빠른 모습을 보이고 있다. 캐시 메커니즘의 목표가 읽기 명령을 빠르게 수행하는 것이 기 때문에 읽기 명령에서 월등한 성능 향상을 보인다.

Random write는 큰 성능 향상이 없으며, 꽤 많은 음수가 발생하는데, 이는 캐시 오버헤드가 원인이다. 아무래도 캐시 기법은 읽기 명령에 초점이 맞추어져 있어, 쓰기 명령의 경 우 성능 저하가 일어날 수 있다.

Backward read는 대체로 좋은 성능을 보인다. 아무래도 $\mathrm{SSD}$ 캐시로 인한 효과가 크다. Record re-write는 다른 write 명령과 같이 캐시 작업의 오버헤드로 낮은 성능을 보 이는 구간이 존재한다. 음수가 아닌 구간도 성능 차이가 적 기 때문에 캐시로 인한 효과는 미미하다. Stride read는 읽 기 명령이라서 대부분 캐싱을 통한 성능 향상을 얻었다. 몇 부분은 캐시 효과를 보지 못하였지만, 전체적인 패턴이 그 렇지 않은 것으로 보아, cache miss로 보인다.

Fwrite의 경우 테스트 데이터 크기가 작을 때는 약간 좋 은 성능을 보이나, 크기가 커지면서 비슷한 성능을 보인다. $\mathrm{Re}-\mathrm{fwrite}$ 는 캐시 효과는 거의 없으며 일반 하드디스크와 비슷한 성능을 보인다. Fread는 일반 읽기 명령과 같이 모 든 구간에서 빠른 성능을 보인다. 다른 읽기 명령과 달리 음수가 하나도 없는 것으로 보아 운영체제 캐시와 $\mathrm{DM}$-cache의 시너지 효과가 나타난 것으로 판단한다. 다만 블록 크기가 작을 때 테스트 데이터가 크면 그 성능이 비교 적 크지 않다. Re-fread는 모든 명령 중 최고로 캐시 효과 를 본 명령으로 거의 모든 상황에서 큰 성능 향상을 보인다. 시스템 버퍼를 사용하면서 $\mathrm{SSD}$ 캐시 효과가 더불어 일어나 이중 캐시가 성능을 효과적으로 향상시켰다.

\section{3) 가상 머신에서의 IOzone 성능 평가}

가상 머신에서의 DM-cache 효율을 알아보기 위해 가상 머신의 guest OS에서 DM-cache 성능을 측정했다. Fig. 3에 서 나타나듯이 그 성능은 일반 운영체제에 비해 미흡하다. 일반 운영체제에서 $79.73 \%$ 확률로 성능이 향상된 반면 가상 머신에서는 $56.73 \%$ 에 불과하다. 성능 향상률도 평균 $12.2 \%$ 덜 향상되었다. 


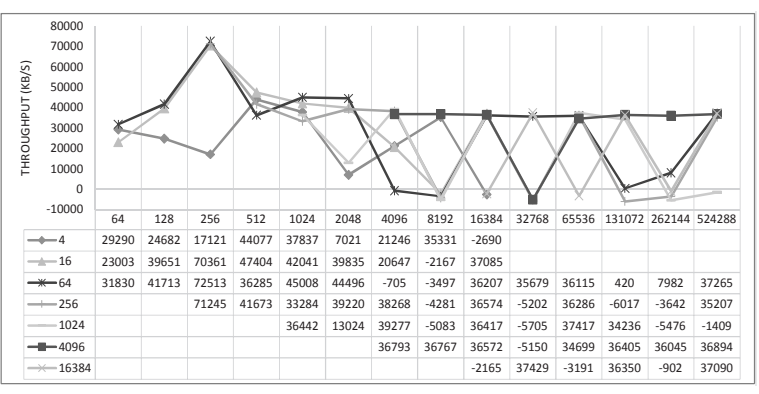

(a) Normal write

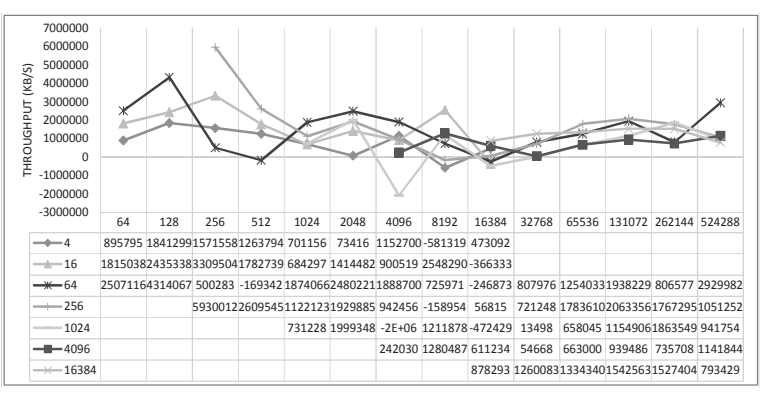

(c) Normal read

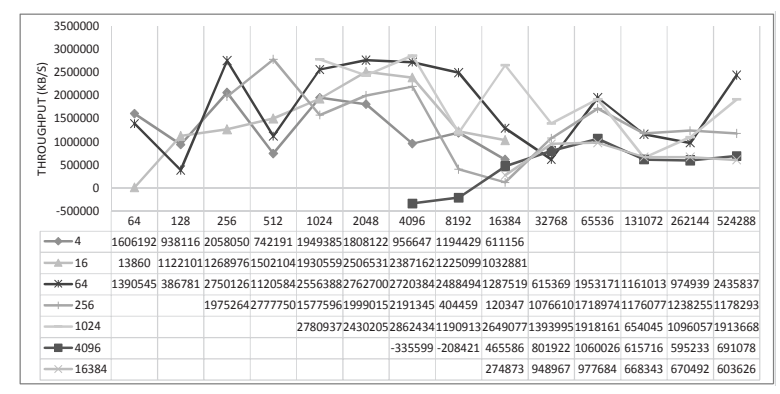

(e) Random read

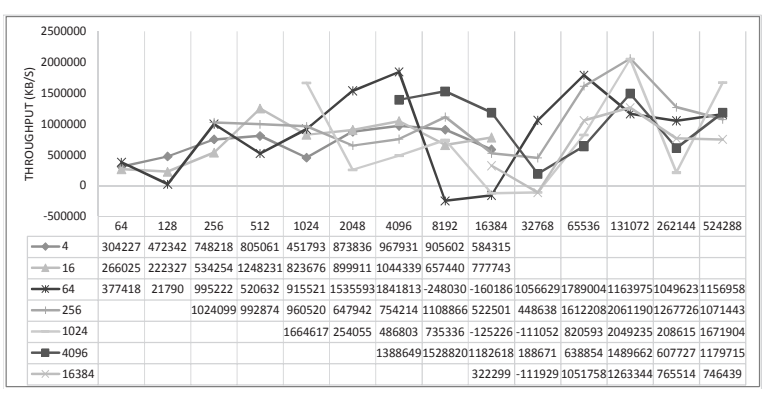

(g) Backward read

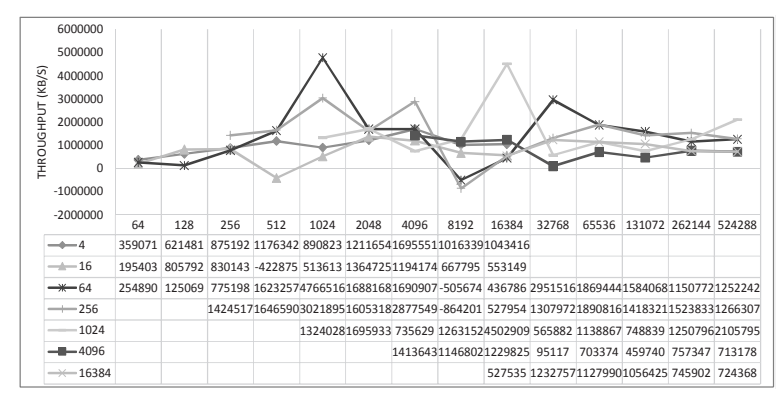

(i) Stride read

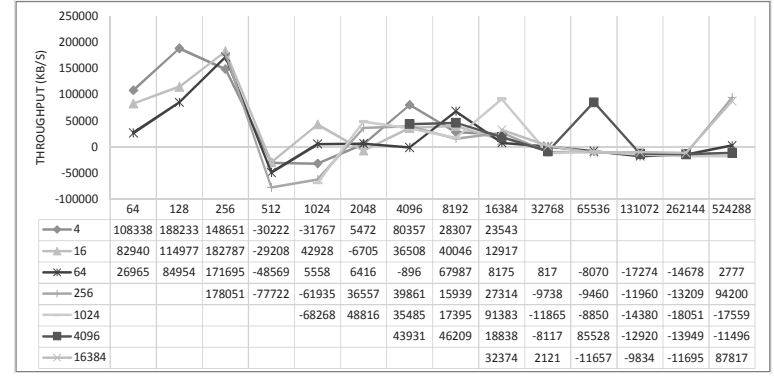

(b) Re-write

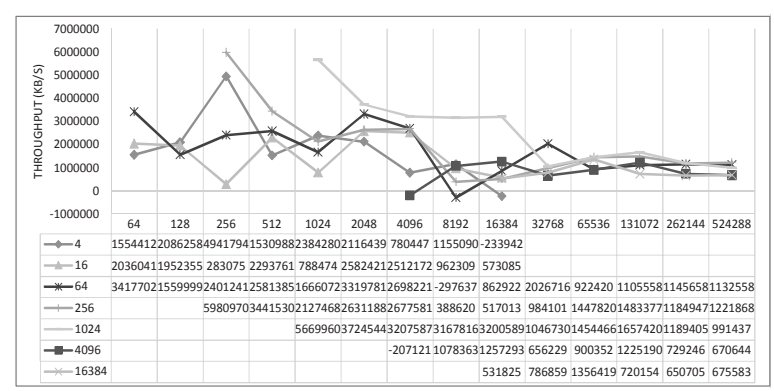

(d) Re-read

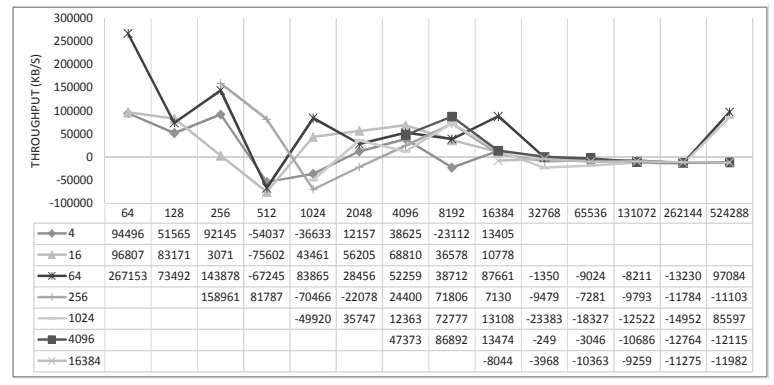

(f) Random write

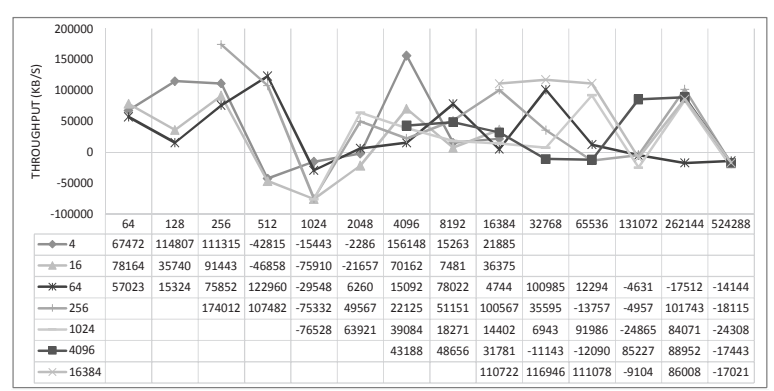

(h) Record re-write

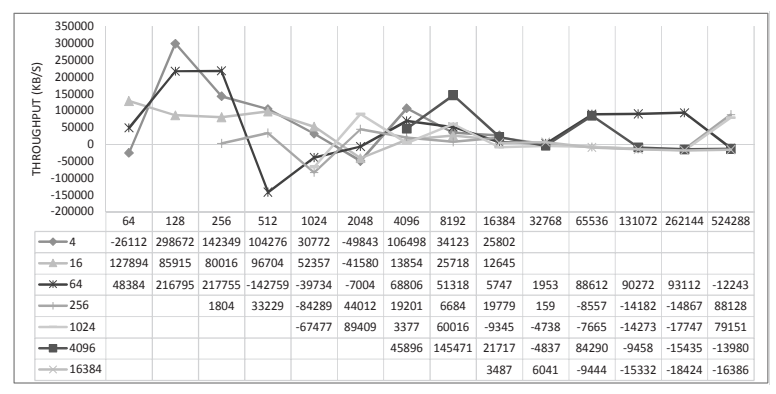

(j) Fwrite 


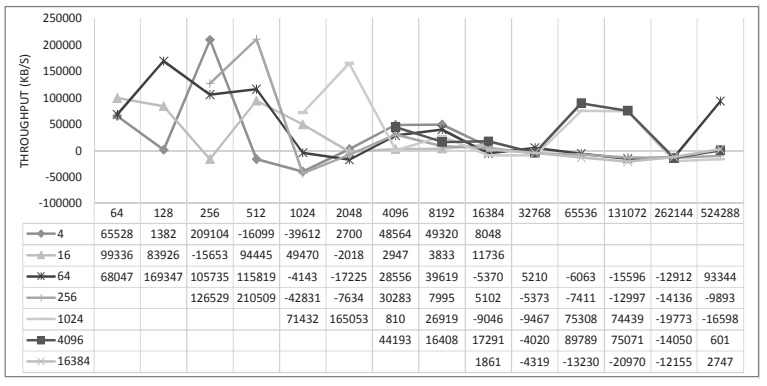

(k) Re-fwrite

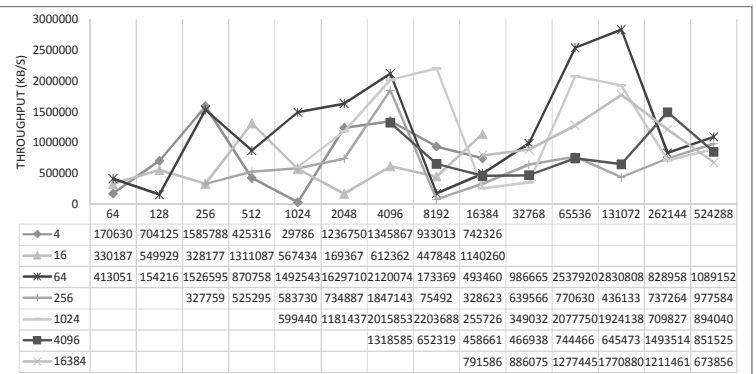

(I) Fread

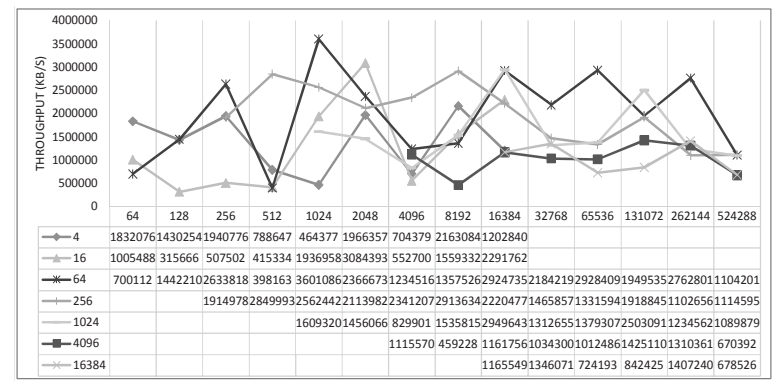

(m) Re-fread

Fig. 2. Improved throughput of disk by DM-cache

(vertical axis of the charts: throughput, vertical axis of the tables: block size, horizontal of the charts and tables: test data size)

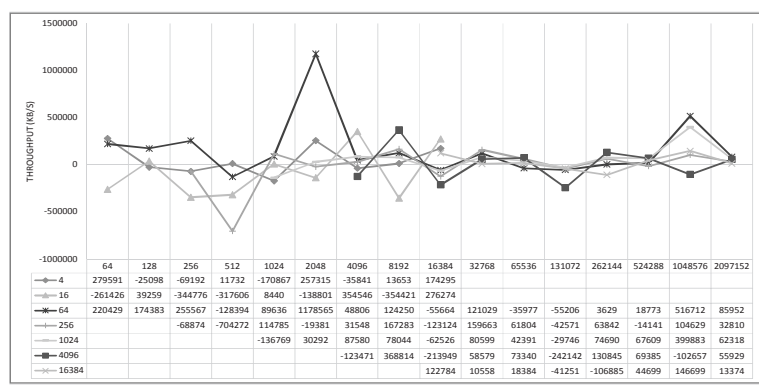

(a) Normal write

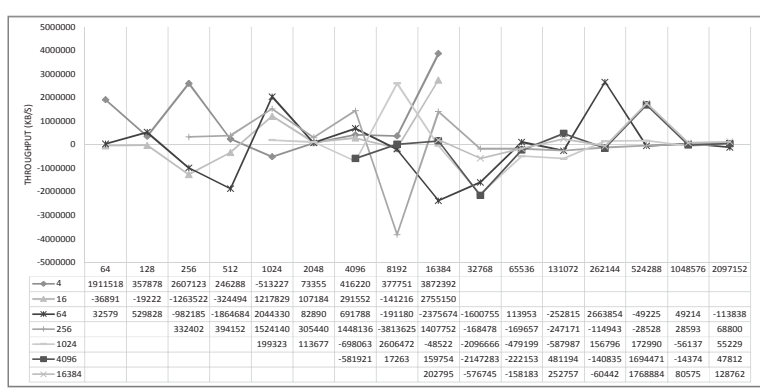

(c) Normal read

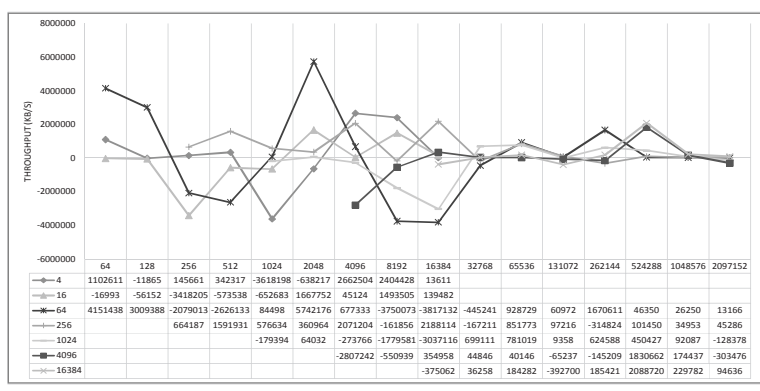

(e) Random read

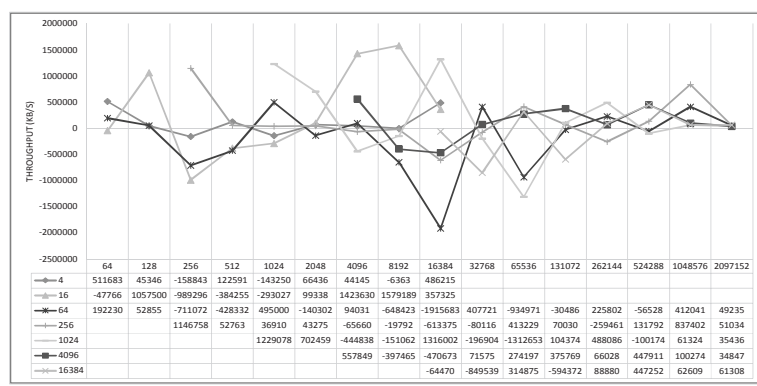

(b) Re-write

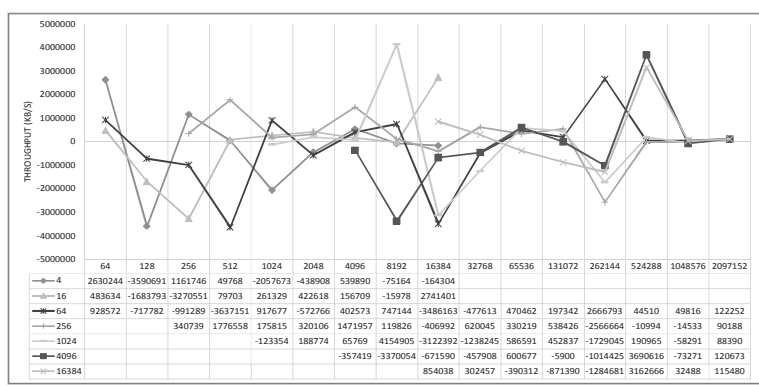

(d) Re-read

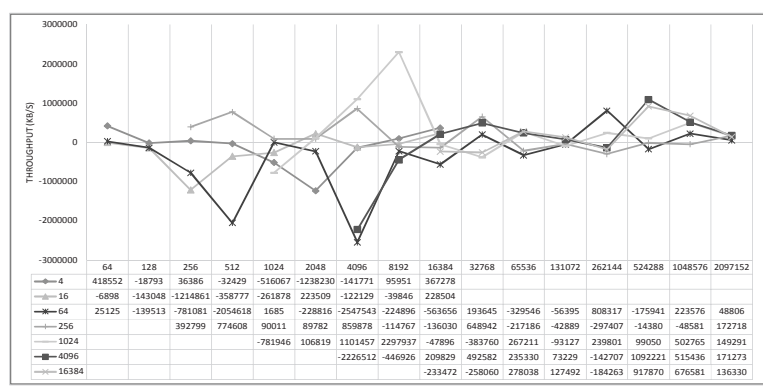

(f) Random write 


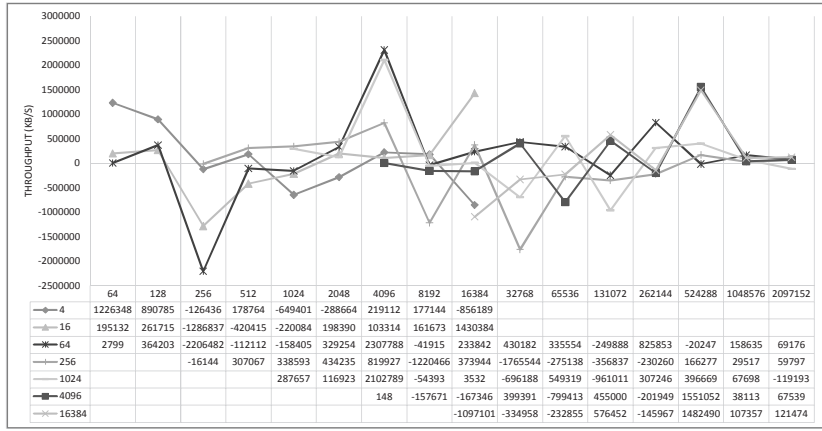

(g) Backward read

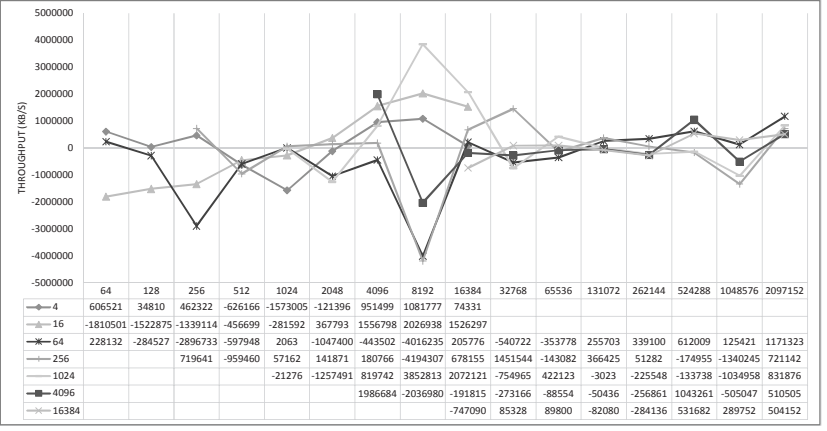

(h) Record re-write

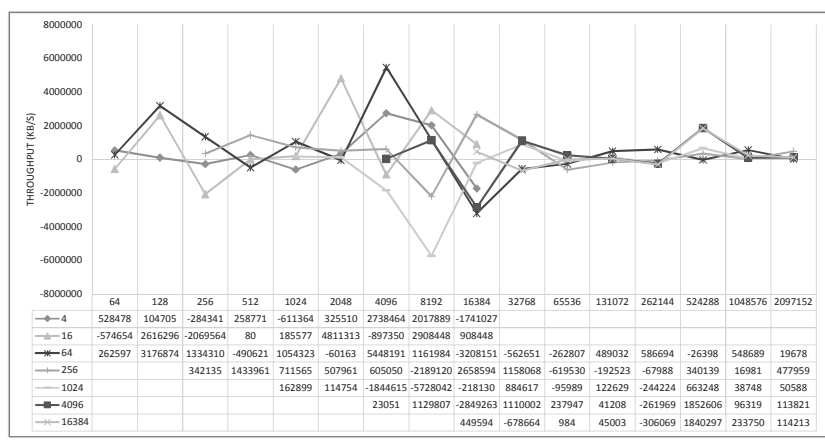

(i) Stride read

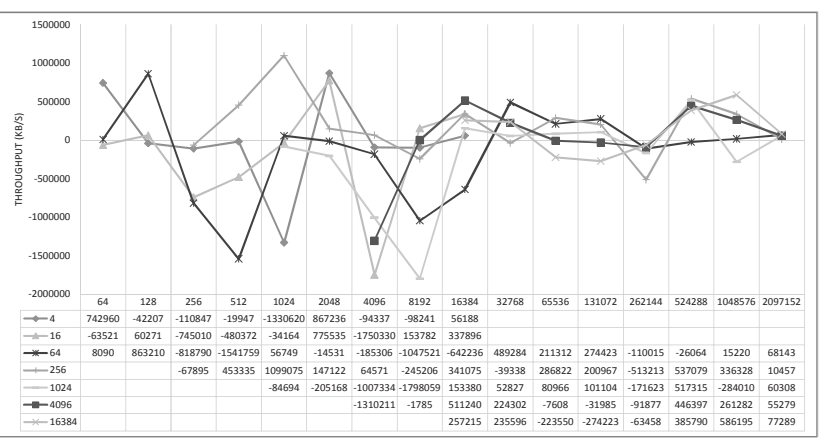

(j) Fwrite

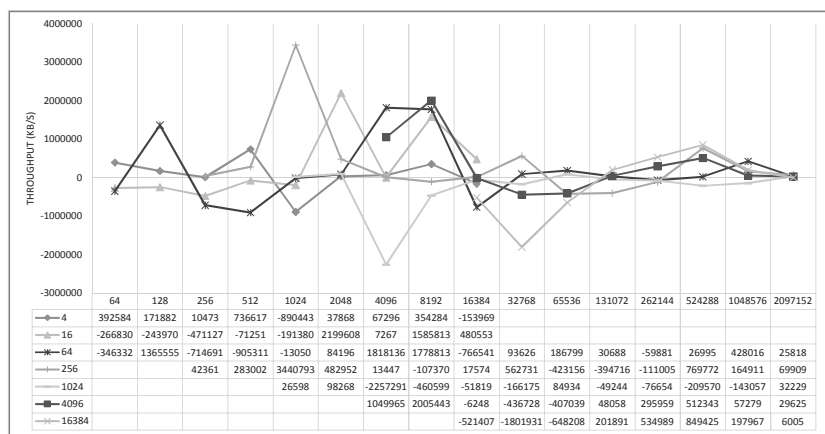

(k) Re-fwrite

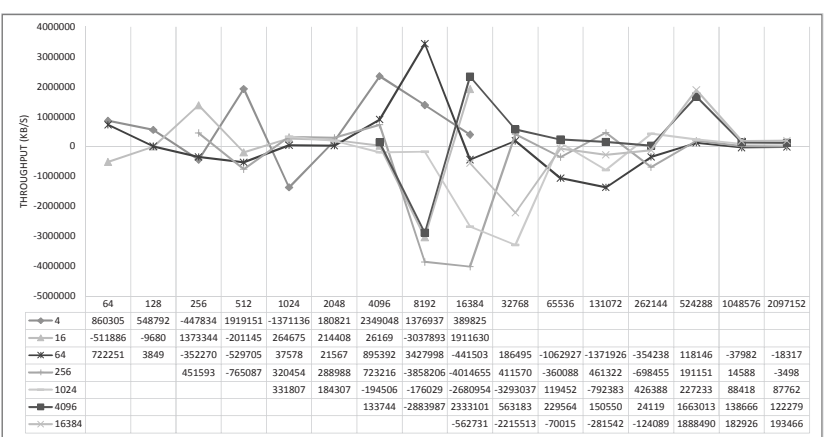

( I) Fread

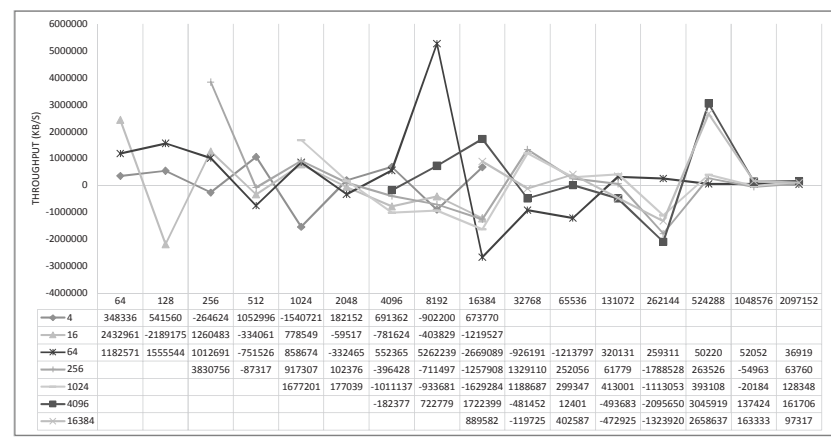

(m) Re-fread

Fig. 3. Improved throughput of disk by DM-cache on virtual machine guest OS

(vertical axis of the charts: throughput, vertical axis of the tables: block size, horizontal of the charts and tables: test data size) 
Normal write에서 테스트 데이터의 크기가 작으면 높은 성능을 보였던 반면 가상 머신에서는 어떤 구간에서도 큰 차이를 보이지 않는다. $\mathrm{Re}^{-} \mathrm{write}$ 역시 마찬가지이며, 음수가 많고 커서 더 나쁜 성능을 보인다고 판단할 수 있다.

읽기 명령인 normal read와 re-read에서도 특별한 성능 향상을 보이지 않았다. 특히 re-read에서의 성능 향상은 캐 시 메커니즘을 사용하는 목표임에도 불구하고 성능 향상이 전혀 없다. 이런 모습에서 $\mathrm{DM}-$ cache로 인해 불필요한 오버 헤드만 생길 뿐 캐시 효과는 전혀 없음을 알 수 있다.

Backward read와 record re-write에서도 성능 향상을 볼 수 없다. Record re-write에서는 절반 이상이 음수가 나올 정도로 낮은 성능을 보인다. 아무래도 캐시 오버헤드와 겹 치면서 일반 하드디스크보다 응답 시간이 더 길다.

Stride read 역시 다른 읽기 명령과 마찬가지로 별다른 캐시 효과를 보지 못하였다. Fwrite와 fe-fwrite, fread, re-fread까지도 특별한 효과를 보이지 못하고 있다. 특히나 fread와 re-fread는 음수가 전혀 없을 정도로 모든 경우에 캐시를 통한 성능 향상을 얻었으나, 가상 머신에서는 효과 를 찾을 수 없다.

가상 머신에서는 DM-cache의 효과를 전혀 발견할 수 없 다. 가장 먼저 원인으로 지목되는 점은 파일의 데이터 블록 과 메타데이터 블록이 실제 디스크에서 구분되어있지 않다 는 점이다. Guest $\mathrm{OS}$ 는 몇 개의 큰 이미지 파일을 가상 디 스크로 인식한다. 즉, guest OS 내부의 파일은 이미지 파일 의 데이터 블록 중 일부분일 뿐이다. 이런 구성으로 인해, guest OS에서 파일에 접근하면, host OS에 있는 DM-cache 관점에서는 데이터 블록 일부분에 접근하는 것으로 판단된 다. 이때 guest OS는 메타데이터 블록에 접근하지만, DMcache는 데이터 블록에 접근한다고 생각하는 시맨틱 갭 (semantic gap)이 생긴다. 또한, guest OS는 순차적으로 기 록되어있다고 생각할지라도 실제 디스크에는 순차적이 아닐 수 있다. 이 문제는 DM-cache 정책에 순차 접근과 랜덤 접 근을 구별하는 정책에 영향을 미친다. 이 두 원인이 대표적 이며, 가상화 기술의 종류에 따라서 원인 분석이 별도로 이 루어져야 한다.

현재 특수한 시스템뿐만 아니라 개인 컴퓨터에서도 가상 머신을 사용하며, 모바일 기기까지 가상화 기술을 이용하 는 만큼 가상 머신이 없는 기기는 없다고 할 수 있다. 가 상 머신의 디스크 요청 처리량은 서비스 품질이나 사용자 경험 측면에서 매우 중요한 요소이기 때문에 가상 머신에 서 사용하지 못하는 DM-cache는 널리 보편화될 수 없다. 실제로 관련 연구가 진행되고 있는데[14], 데이터센터 관점 에서 연구하기 때문에 개인 사용자의 기기에는 적합한 정책 이 아니다.
일반 운영체제에서의 DM-cache는 어느 정도 효과를 보 고 있지만, 쓰기 명령에서는 오버헤드가 문제되고 있으며, 읽기 명령 또한 모든 구간에서 높은 성능을 보이지는 못했 다. 기본 정책인 write-back의 한계로 인지하고, 더욱 적합 한 정책이 필요하다. 또한, 가상 머신에서 디스크 요청 처리 성능이 중요함에도 불구하고 전혀 효과를 보지 못하기 때문 에 가상 머신에 적합한 정책이 연구되어야 한다.

\section{5. 결 론}

리눅스 정식 커널에 포함된 $\mathrm{DM}-$ cache 정책이 아직 효과 적이지 못한 만큼, 정책 연구가 필요하다. 그에 앞서 기존 정책의 한계를 알아보고자 다양한 명령을 일반 운영체제와 가상 머신 guest OS에서 실행하고 성능을 평가했다. 그 결 과로 일반 운영체제에서 읽기 명령은 캐시 효과를 보고 있 으나, 쓰기 명령은 오버헤드로 인해 그 효과가 미미한 점을 발견했다. 가상 머신에서는 모든 명령에서 캐시 효과를 보 지 못하였다. 그러므로 가상 머신을 위한 $\mathrm{SSD}$ 캐시 정책 연구가 필요함을 시사한다.

가상 머신에서 DM-cache의 효과가 미미한 원인은 가상 화 기술에 따라 매우 달라진다. 앞으로 우리는 다양한 가상 화 기술에서 원인을 분석하고, 각 기술에 최적화된 대책에 대한 연구를 진행할 계획이다.

\section{References}

[1] K. S. Venkataraman, Z. Tong, Z. Wenzhe, S. Hongbin, and Z. Nanning, "Scheduling Algorithms for Handling Updates in Shingled Magnetic Recording," IEEE International Conference on Networking, Architecture and Storage, pp. 205-214, Jul., 2013.

[2] J. Lee, S. Han, J. Ryu, and K. Kang, "Strategy to Reduce I/O Access Time of Applications in Virtual Machines," IT Convergence and Security, pp.1-2, Dec., 2013.

[3] T. Feldman, G. Gibson, "Shingled Magnetic Recording: Areal Density Increase Requires New Data Management," ;login: Vol.39, No.1, pp.22-30, Jun., 2013.

[4] M. H. Kryder, E. C. Gage, T. C. McDaniel, W. A. Challener, R. E. Rottmayer, G. Ju, Y.-T. Hsia, and M. F. Erden, "Heat Assisted Magnetic Recording," Proceedings of the IEEE, Vol.96, No.11, pp.1810-1835, Nov., 2008.

[5] E. Dobisz, Z. Bandic, T. Wu, and T. Albrecht, "Patterned Media: Nanofabrication Challenges of Future Disk Drives," Proceedings of the IEEE, Vol.96, No.11, pp.1836-1846, Nov., 2008. 
[6] P. Llopis, J. G. Blas, F. Isaila, and J. Carretero, "Survey of Energy-Efficient and Powerproportional Storage Systems," The Computer Journal of Oxford, Jun., 2013.

[7] Y. Deng, "What is the Future of Disk Drives, Death or Rebirth?, ACM Computing Surveys, Vol.43, No.3, pp. 23:1-23:27, Apr., 2011.

[8] J. Wang, W. Lai, and X. Meng, "SFCM: A SSD-Friendly Cache Management Policy for Hybrid Storage Systems," Springer Berlin Heidelberg, Vol.7901, pp.16-27, 2013.

[9] J. Reineke, D. Grund, "Sensitivity of Cache Replacement Policies," ACM Transaction on Embedded Computer Systems, Vol.12, No.1s, pp.42:1-42:18, Mar., 2013.

[10] Desktop SSHD: 4TB Hybrid Drive Upgrade | Seagate, http://www.seagate.com/internal-hard-drives/ solid-state-hybrid/desktop-solid-state-hybrid-drive/

[11] Y. Joo, J. Ryu, S. Park, H. Shin, and K. Shin, "Rapid Prototyping and Evaluation of Intelligence Functions of Active Storage Devices," IEEE Trans. on Computers, Vol.99, pp.1-14, Apr., 2013.

[12] bcache, http://bcache.evilpiepirate.org/

[13] DM-cache, https://www.kernel.org/doc/Documentation/devicedevice-mapper/cache.txt

[14] D. Arteaga, D. Otstott, and M. Zhao, "Dynamic Block-level Cache Management for Cloud Computing Systems," USENIX Conference on File and Storage Technologies, Feb., 2012.

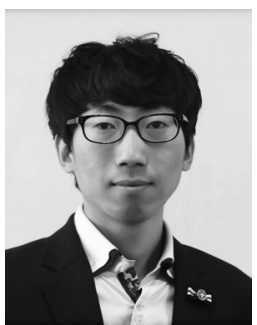

\section{이 재 면}

e-mail : jaemyoun@hanyang.ac.kr 2012년 한양대학교 컴퓨터공학과(학사) 2012년 현 재 한양대학교 컴퓨터공학과 석 - 박사통합과정

관심분야: Energy Efficient Computing Platforms, Power-aware Storage Systems, Cyber-Physical Systems

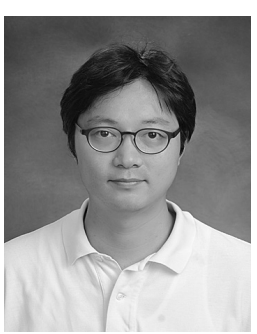

\section{강 경 태}

e-mail : ktkang@hanyang.ac.kr 1999년 서울대학교 전산과학전공(학사) 2001년 서울대학교 컴퓨터공학부(석사) 2007년 서울대학교 컴퓨터공학부(박사) 2008년 Coordinated Science Lab. University of Illinois at Urbana-Champaign(박사후연구원)

2010년 Dept. Computer Science, University of Illinois at UrbanaChampaign(박사후연구원)

2011년 현 재 한양대학교 컴퓨터공학과 조교수

관심분야: Cyber-Physical Systems, Mobile Computing 